\title{
Synthesis, characterization and catalytic activity of furosemide-functionalized ferrite on the sedimentation behavior of starch
}

\author{
S. Palanikumar $\cdot$ B. Meenarathi $\cdot$ \\ L. Kannammal • R. Anbarasan
}

Received: 23 November 2013/Accepted: 22 January 2014/Published online: 21 February 2014

(C) The Author(s) 2014. This article is published with open access at Springerlink.com

\begin{abstract}
Furosemide-functionalized nanoferrite was synthesized and characterized by various analytical techniques. The furosemide-functionalized ferrite was used to settle down the starch particles under three different $\mathrm{pH}$. Thus, obtained starch/ $\mathrm{Fe}_{3} \mathrm{O}_{4}$ nanocomposites were characterized by Fourier transform infrared spectroscopy (FTIR), fluorescence spectroscopy, scanning electron microscopy (SEM), differential scanning calorimetry (DSC) and thermogravimetric analysis (TGA). The sedimentation velocity of starch in the presence of furosemide-functionalized $\mathrm{Fe}_{3} \mathrm{O}_{4}$ was critically compared with the available literature value and the results are discussed in detail. The high sedimentation velocity of starch under the influence of gravitational force and the external magnetic force is studied. The starch-coated ferrites exhibited the lower vibrating sample magnetometer (VSM) value. This novel research work will bring out a new methodology in the field of starch materials.
\end{abstract}

Keywords Synthesis - Characterization .

Functionalization $\cdot$ Starch $\cdot$ Sedimentation

\section{Introduction}

Food emulsion contains starch and protein as the major component in our daily life. Starch is an important bio-food material for people particularly south Indians as rice and

Electronic supplementary material The online version of this article (doi:10.1007/s13204-014-0294-5) contains supplementary material, which is available to authorized users.

S. Palanikumar · B. Meenarathi · L. Kannammal ·

R. Anbarasan $(\square)$

Department of Polymer Technology, Kamaraj College of

Engineering and Technology, Virudhunagar 626001,

Tamil Nadu, India

e-mail: anbu_may3@yahoo.co.in potato. Such a life saving starch is a biopolymer present in seeds, stems and roots of plants including wheat, barley and corns in the form of minute granules as renewable resources. In most of the industries, starch is extracted from cereal and tubule roots. Various methodologies are adopted for the isolation and purification of starch as mentioned here. For example in 1999, Closs et al. (1999) studied the phase separation and rheologies of starch/galactomannan in an aqueous system. Sajeev et al. (2002) reported the gravity settling velocity of starch in an aqueous suspension. Extraction of cassava starch explained the modality (Da et al. 2010). Sedimentation, microfiltration and reverse osmosis were done for the washing of corn starch (Madariaga and Aquirre 2011), using different ammonium chloride-based flocculants for the isolation of starch from its resource material (Wei et al. 2008). During the isolation and purification of starch larger quantity of water is consumed and, hence, the water resistivity has direct relationship to the chemical potential of water, and hence leads to the degradation of carbohydrates in the starch. It means that during the long sedimentation process, the water molecules slowly degrade the structure of carbohydrate in the presence of water-living microbial system. This type of microbial activity leads to the formation of low-quality starch as well as wasting of starch. It was calculated that around $5 \%$ of starch was wasted by the microbial activities. In order to save such a food material, various methodologies have been used. By thorough literature survey, we could not find any report based on the magnetic sedimentation of starch molecules.

The nanosized iron oxide has many unique properties such as high coercivity, low curie temperature and high magnetic susceptibility values with excellent superparamagnetism. Such a nice candidate can be synthesized by different methods (Sun et al. 2007; Prakash et al. 2004;

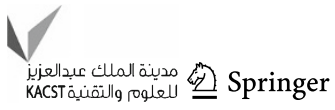


Li et al. 2005; Bin et al. 2009; Tian et al. 2010). Recently, the magnetic nanoparticles are found to have important biomedical applications such as MRI agent (Huang and Juang 2011; Mos et al. 2007), detection of biological cavities (He et al. 2005), etc. Due to the absence of surface of functionalities, the applications of magnetic nanoparticles are restricted to some extent. This problem can be outwitted by the functionalization process. $\mathrm{Fe}_{3} \mathrm{O}_{4}$ nanoparticles were functionalized by propargyl acid (Zhou et al. 2008), dimercaptosuccinic acid (Kim et al. 2010), oleic acid (Xiao et al. 2010), ethylenediamine (Gang et al. 2010), streptavidin (Koussi et al. 2007), daunomycin (Chen et al. 2008), polystyrene (Jiang et al. 2007) and oleylamine (Klokkenburg et al. 2007). On thorough literature survey, we could not find any report based on furosemide-functionalized $\mathrm{Fe}_{3} \mathrm{O}_{4}$ nanoparticle. The novelty of the present investigation is that furosemide-functionalized $\mathrm{Fe}_{3} \mathrm{O}_{4}$ nanoparticle was synthesized by co-precipitation method and the same was used for the sedimentation of starch particles.

Functionalization of $\mathrm{Fe}_{3} \mathrm{O}_{4}$ by furosemide is simply a surface reaction. Furosemide contains one $\mathrm{NH}_{2}, \mathrm{SO}_{2}$, $\mathrm{CO}_{2} \mathrm{H}, \mathrm{NH}$, ether and one $\mathrm{Cl}$ atom. The $\mathrm{NH}$ group of furosemide interacts with the $\mathrm{Fe}_{3} \mathrm{O}_{4}$ surface. The $\mathrm{OH}$ group of starch can interact either with the amino group or $\mathrm{SO}_{2}$ or ether linkage through secondary forces of attraction. Furosemide offers more functionalities for starch molecules. The $\mathrm{OH}$ group of starch can interact with any of the functional groups of furosemide.

\section{Experimental}

\section{Materials}

The raw materials required for the preparation of $\mathrm{Fe}_{3} \mathrm{O}_{4}$ nanoparticles are as follows: ferrous sulfate $\left(\mathrm{FeSO}_{4}\right)$, ferric chloride $\left(\mathrm{FeCl}_{3}\right)$ and sodium hydroxide $(\mathrm{NaOH})$ were purchased from $\mathrm{CDH}$, India. The double distilled (DD) water was used for the solution preparation work. The ferrite nanoparticle was functionalized in the presence of furosemide (Ranbaxy, India). The sedimentation velocity of starch (purchased from Himedia chemicals, India) was studied under three different $\mathrm{pH}$ values at 2.5, 7.1 and 12.0.

Synthesis of ferrite and furosemide-functionalized ferrite

In the first step, pristine ferrite nanoparticles were synthesized by the co-precipitation method. The procedure is given below: 5 -g ferrous sulfate in 50-mL DD water was taken in a $250-\mathrm{mL}$ round bottom (RB) flask. 10 -g ferric chloride in $50-\mathrm{mL}$ water was added slowly into the $\mathrm{RB}$ flask. The slow addition was continued for $30 \mathrm{~min}$ at $45{ }^{\circ} \mathrm{C}$
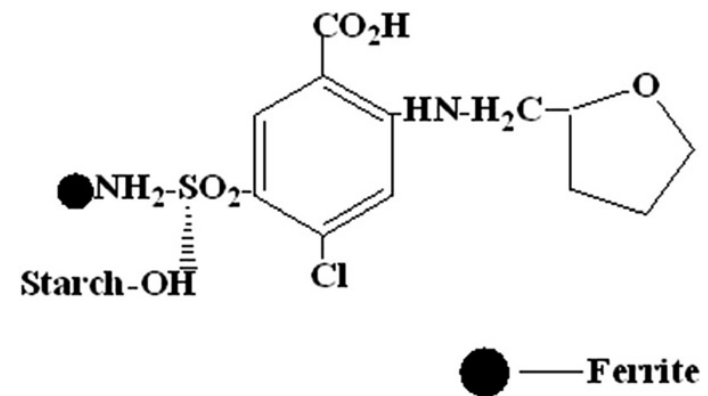

Scheme 1.

under nitrogen atmosphere under mild stirring condition. After the complete mixing, the temperature of the reaction system was reduced to room temperature with the simultaneous addition of $1 \mathrm{M} \mathrm{NaOH}$ solution under vigorous stirring. While adding sodium hydroxide, the nucleation process started and there is a formation of ferrite nanocrystals (Koussi et al. 2007). The ferrite formation can be confirmed by the appearance of the black coloration while adding $\mathrm{NaOH}$ solution. Now the $\mathrm{pH}$ was adjusted to 12.5 . After $2 \mathrm{~h}$ of nucleation reaction, the contents were stirred for another $1 \mathrm{~h}$. At the end of the reaction, the contents were transferred to a $500-\mathrm{mL}$ beaker and the same was kept on a magnetic bar. After a certain period of time, the black color precipitate settled down and the supernatant liquid was removed by pipetting without any disturbance in the medium. Thus, the obtained black-colored precipitate was washed thrice with 100-mL DD water. This process was repeated to remove the impurities from the system. After the complete removal of water, the ferrite nanoparticles were dried at $110{ }^{\circ} \mathrm{C}$ for $8 \mathrm{~h}$. Thus, obtained fine black powder of ferrite was weighed and stored in a zipper lock bag. In the second step, the furosemide-functionalized ferrite nanoparticle was synthesized. Here also one can follow the above-mentioned procedure but in the presence of $2-\mathrm{g}$ furosemide in 20-mL DD water.

2-g potato starch was dissolved in 100-mL DD water. The above-synthesized furosemide-decorated ferrite nanoparticles were added slowly under vigorous stirring condition. The furosemide-functionalized ferrite can be loaded at different percentage weight. After the reaction, the contents were evaporated to dryness. The final product, starch/furosemide-functionalized ferrite nanoparticle systems were dried, weighed and stored in a zipper lock cover.

$\mathrm{Fe}_{3} \mathrm{O}_{4}$ is a biocompatible nano metal oxide. It is sensitive towards the applied magnetic force. For $2 \mathrm{~g}$ of starch, $0.01 \mathrm{~g}$ of furosemide-functionalized $\mathrm{Fe}_{3} \mathrm{O}_{4}$ was added $(0.5 \%)$. This is a negligible amount when compared with the amount of starch. It is also used to improve the iron content in the human body. It is used to improve the mechanical strength of the bones and teeth of humans. 
Hence, it is not necessary to remove the $\mathrm{Fe}_{3} \mathrm{O}_{4}$ from the starch after its isolation from the medium.

\section{Characterization}

FTIR spectrum was taken using Shimadzu $8400 \mathrm{~S}$, Japan model instrument from 4,000 to $400 \mathrm{~cm}^{-1}$ by $\mathrm{KBr}$ pelletization method. Jasco V-570 instrument was used for UVvisible spectrum measurements. 2-mg sample was dissolved in 10-mL DD water under ultrasonic irradiation for $10 \mathrm{~min}$ and subjected to UV-visible spectral measurements. Fluorescence spectrum (excited at $290 \mathrm{~nm}$ ) was measured with the help of Jasco Model FP-6000, Japan, instrument from 300 to $700 \mathrm{~nm}$. X-ray diffraction (XRD, XS08, Bruker, USA) was recorded with an advanced instrument and scanning from the $2 \theta$ value of $10^{\circ}-80^{\circ}$ at a scanning rate of $2 \% \mathrm{~min}$. The surface morphology of the samples was scanned by SEM (JSM 6300, JEOL model) instrument. Magnetic measurements were carried out with a superconducting quantum interference device magnetometer (Lakesore-7410-VSM, USA) with magnetic fields up to $7 \mathrm{~T}$ at $32{ }^{\circ} \mathrm{C}$.

\section{Sedimentation study}

The settling velocity of starch in the presence of furosemide-functionalized ferrite nanoparticle under three different $\mathrm{pH}$ was determined using the following formula (Sajeev et al. 2002).

$v_{0}=\frac{g d_{\mathrm{s}}^{2}\left(\rho_{\mathrm{s}}-\rho_{\mathrm{w}}\right)}{18 \mu_{\mathrm{w}}}$

where $V_{0}$ is free-falling velocity in $\mathrm{m} \mathrm{s}^{-1}, g$ acceleration due to gravity in $\mathrm{m} \mathrm{s}^{-2}, d_{\mathrm{s}}$ diameter of starch particle, $\rho_{\mathrm{s}}$ density of starch particle in $\mathrm{kg} \mathrm{m}^{-3}, \rho_{\mathrm{w}}$ density of water in $\mathrm{kg} \mathrm{m}^{-3}$, and $\mu_{\mathrm{w}}$ viscosity of water in $\mathrm{kg} \mathrm{m}^{-1} \mathrm{~s}^{-1}$.

\section{Results and discussion}

For the sake of convenience, the present results and discussion part is sub-divided into two parts namely, (1) characterizations of furosemide-functionalized ferrite nanoparticles, (2) characterizations of ferrite-furosemidestarch nano composites.

Characterizations of furosemide-functionalized ferrite nanoparticles

\section{FTIR study}

The functional groups present in the ferrite before and after functionalization can be determined by FTIR spectroscopy.

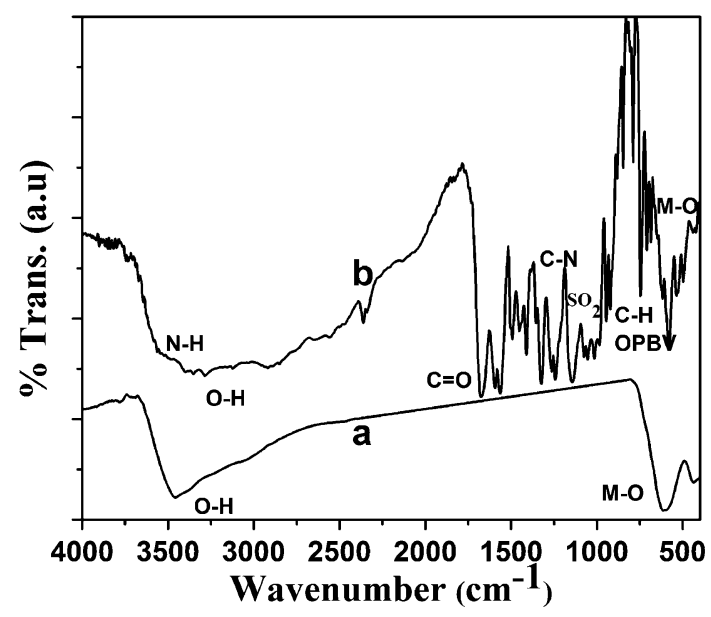

Fig. 1 FTIR spectrum of a pristine ferrite, b furosemide-functionalized ferrite

A broad peak around $3,500 \mathrm{~cm}^{-1}$ (Fig. 1a) explains the $-\mathrm{OH}$ stretching. The $-\mathrm{OH}$ stretching is due to the intercalated water molecules. The $\mathrm{M}-\mathrm{O}$ stretching is observed at $608 \mathrm{~cm}^{-1}$ (Gang et al. 2010). In the case of pristine ferrite, one can see the $\mathrm{OH}$ and $\mathrm{M}-\mathrm{O}$ stretching alone. Figure $1 \mathrm{~b}$ indicates the furosemide-functionalized ferrite. The $\mathrm{N}-\mathrm{H}$ stretchings are observed at $3,454 \mathrm{~cm}^{-1}$. This is in accordance with Gang et al. (2010). The $\mathrm{SO}_{2}$ stretchings are observed around $1,015 \mathrm{~cm}^{-1}$. The $\mathrm{C}-\mathrm{N}$ stretching can be seen at $1,328 \mathrm{~cm}^{-1}$. The $\mathrm{C}=\mathrm{O}$ stretching of carboxyl group appeared at $1,676 \mathrm{~cm}^{-1}$. The cyclic $\mathrm{C}-\mathrm{O}-\mathrm{C}$ ether linkage and $\mathrm{C}-\mathrm{H}$ out of plane bending vibration can be seen at 1,138 and $749 \mathrm{~cm}^{-1}$, respectively. The $\mathrm{M}-\mathrm{O}$ stretching is observed at $570 \mathrm{~cm}^{-1}$. Thus, the FTIR spectrum confirms the functionalization of ferrite by furosemide.

\section{$U V$-visible spectroscopy}

Figure $2 \mathrm{a}$ represents the UV-visible spectrum of pristine ferrite which exhibits one broad peak at $380 \mathrm{~nm}$ corresponding to the ferrite. After the surface functionalization of ferrite, the spectrum exhibits two sharp peaks at 327 and $274 \mathrm{~nm}$ (Fig. 2b). A peak at $274 \mathrm{~nm}$ is associated with the $\pi \rightarrow \pi^{*}$ transition of phenyl ring present in the furosemide. Ferrites are observed at $327 \mathrm{~nm}$. On comparison, the peak corresponding to ferrite is blue shifted due to the surface functionalization and size reduction of ferrite. Ahmad et al. (2009) reported the UV-visible spectrum of ferrite with an absorption peak at $410 \mathrm{~nm}$. But in the present investigation due to the size reduction of ferrite and the encapsulation of ferrite by furosemide, the absorption peak is blue shifted. Figure $2 \mathrm{c}$ confirms the fluorescence spectrum of pristine ferrite at $377 \mathrm{~nm}$ with the intensity value of 7.3 cps. Figure $2 \mathrm{~d}$ declares the 

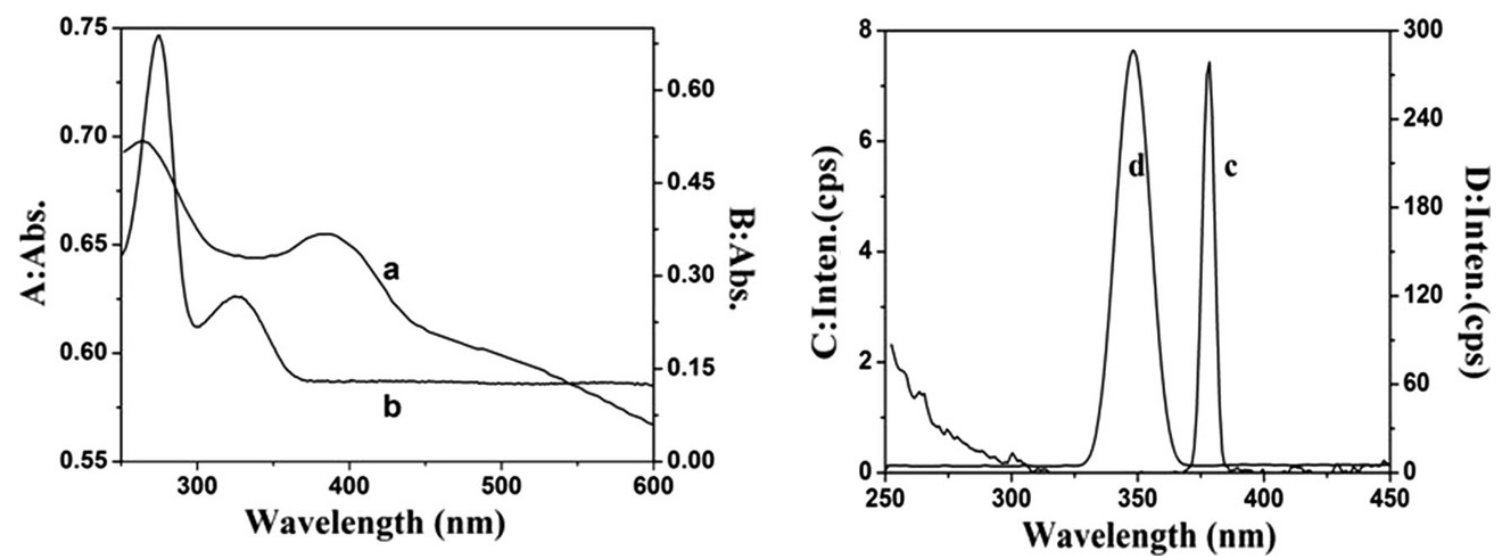

Fig. 2 UV-visible spectrum of a pristine ferrite, $\mathbf{b}$ furosemide-functionalized ferrite and fluorescence emission spectrum of $\mathbf{c}$ pristine ferrite, d furosemide-functionalized ferrite
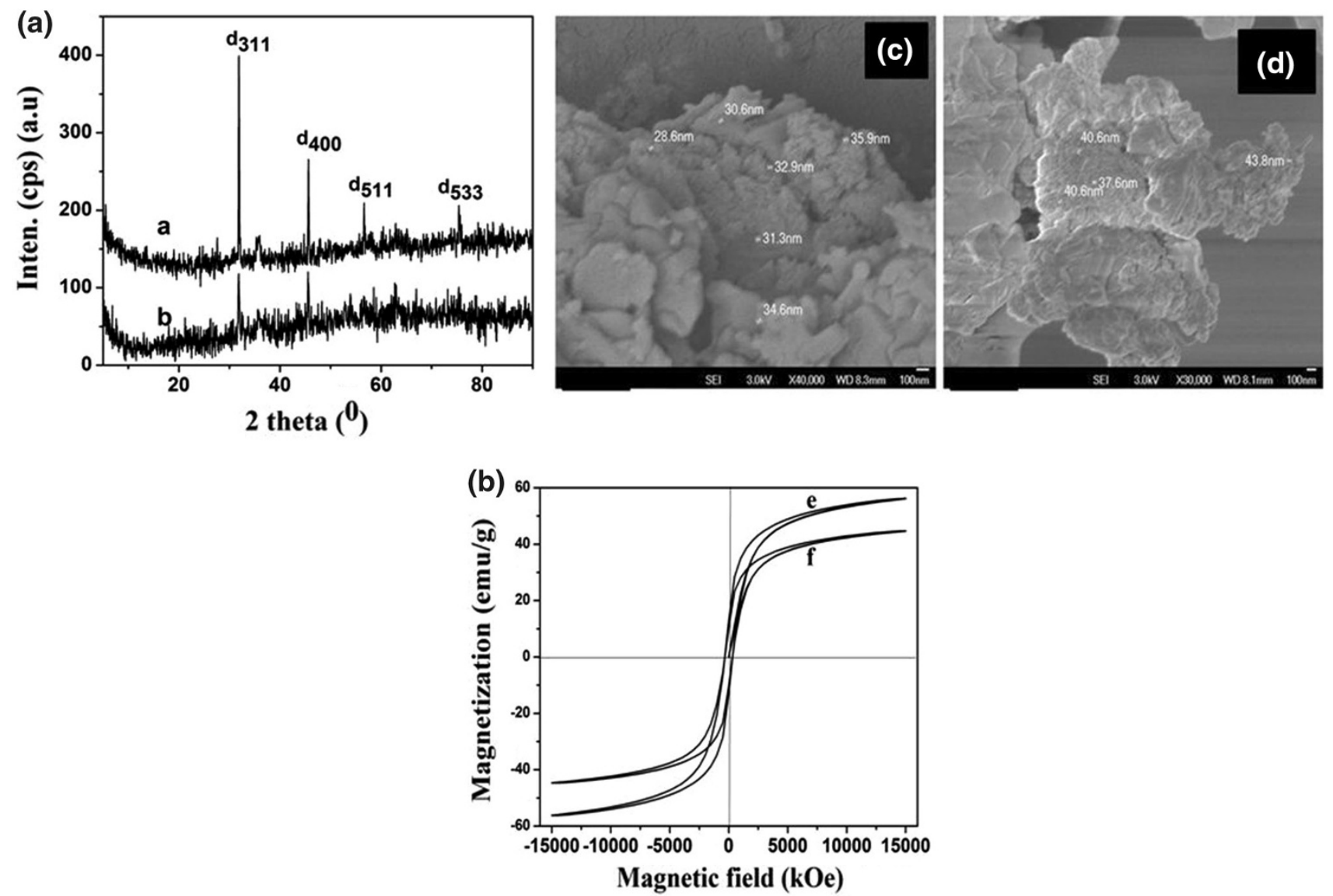

Fig. 3 XRD of a pristine ferrite, $\mathbf{b}$ furosemide-functionalized ferrite, $\mathbf{c}, \mathbf{d}$ FESEM images of furosemide-functionalized ferrite and VSM loop of e pristine ferrite, $\mathbf{f}$ furosemide-functionalized ferrite

fluorescence emissions spectrum of ferrite after functionalization with furosemide at $347 \mathrm{~nm}$ with the fluorescence emission intensity (FEI) of $292 \mathrm{cps}$. On comparison, the ferrite after functionalization with furosemide exhibits high FEI value. The increase in intensity is associated with the surface functionalization of ferrite with furosemide.

\section{XRD profile}

Figure $3 \mathrm{a}, \mathrm{b}$ enumerates the XRD of ferrite before and after functionalization with furosemide. The pristine ferrite (Fig. 3a) exhibits $d_{311}, d_{400}, d_{511}$ and $d_{533}$ crystal planes at $31.8^{\circ}, 45.6^{\circ}, 56.7^{\circ}$ and $75.3^{\circ}$, respectively (Ahmad et al. 2009). The ferrite after functionalization with furosemide 
exhibits the same crystal planes corresponding to the ferrite, but with lesser intensity (Fig. 3b). This can be explained as follows. (1) due to the surface functionalization, (2) the furosemide may intercalate into the basal spacing of ferrite. The XRD results indicate that there is no change in the peak position, which indicates that during the functionalization process there is no delamination or exfoliation of ferrite crystals. It seems that the added furosemide is simply adsorbed on the surface of ferrite. Due to the surface functionalization reaction, the crystallinity of ferrite was disturbed and becomes amorphous. The decrease in crystallinity of ferrite strongly infers that there exists a stable interaction between ferrite and furosemide. Furosemide contains one $\mathrm{NH}_{2}, \mathrm{SO}_{2}, \mathrm{CO}, \mathrm{NH}$ and $\mathrm{Cl}$ group. Among those, amino group is a good metal oxide surface binding group.

\section{FE-SEM analysis}

Figure $3 c, d$ indicates the FE-SEM of furosemide-functionalized ferrite. Here, the size of the ferrite was calculated as $35 \mathrm{~nm}$ approximately with agglomerated structure. This result reveals that the added furosemide simply adheres on the surface of the ferrite.

\section{VSM measurement}

Figure 3 shows the VSM loops of ferrite before and after functionalization with furosemide. The pure ferrite (Fig. 3e) exhibits the VSM value of $53.4 \mathrm{emu} / \mathrm{g}$, whereas ferrite after functionalization with furosemide (Fig. 3f) exhibits the VSM value of $42.7 \mathrm{emu} / \mathrm{g}$. The decrease in magnetization value is ascribed to the surface adsorption of furosemide. Due to the surface functionalization reaction, the added furosemide is coated on the surface of ferrite like a thin film. As a result of encapsulation, the magnetisation value of ferrite was depressed. In 2008, Vinod et al. (2008) studied the VSM of ferrite before and after encapsulation with poly(diacetylene) molecules. They reported that after the encapsulation of ferrite with poly(diacetylene) chains, the VSM value was reduced. Our result is in accordance with their report. In the present investigation, ferrite after the surface functionalization with furosemide the VSM value was decreased. Similar type of observation was noted by Aouak et al. (2013).

Characterizations of ferrite-furosemide-starch nano composites

\section{FTIR study}

The FTIR spectrum explains the functional groups present in the system. Figure $4 \mathrm{a}$ shows the FTIR

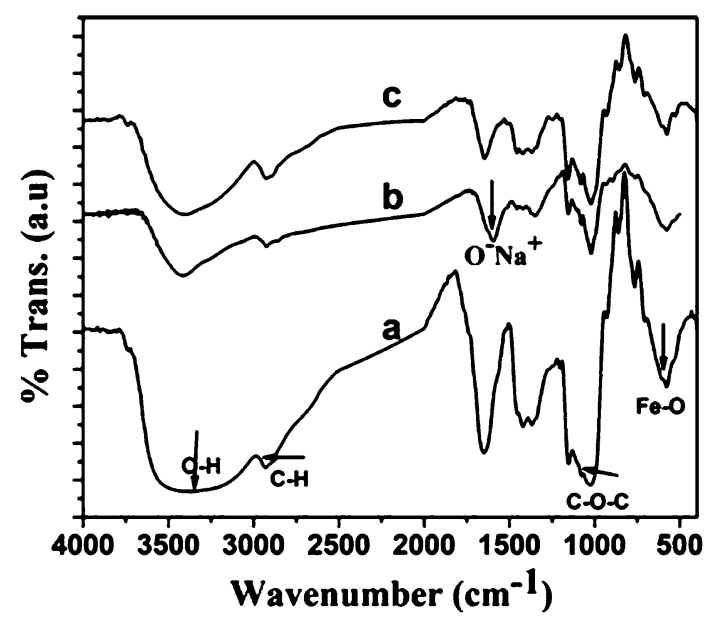

Fig. 4 FTIR spectrum of ferrite-furosemide-starch prepared under a acidic $\mathrm{pH}, \mathbf{b}$ alkaline $\mathrm{pH}$, c neutral $\mathrm{pH}$

spectrum of $\mathrm{Fe}_{3} \mathrm{O}_{4}$-furosemide-starch prepared under acidic $\mathrm{pH}$. The $-\mathrm{OH}$ bending vibration is observed as a broad peak around $3,400 \mathrm{~cm}^{-1}$. A doublet peak at $2,905 \mathrm{~cm}^{-1}$ explains the $\mathrm{C}-\mathrm{H}$ symmetric and antisymmetric stretching of starch. A sharp peak at $1,650 \mathrm{~cm}^{-1}$ is corresponding to the $-\mathrm{OH}$ bending vibration. A peak at $1,393 \mathrm{~cm}^{-1}$ reveals the presence of $\mathrm{C}-\mathrm{H}$ bending vibration. The $\mathrm{C}-\mathrm{O}-\mathrm{C}$ ether linkage of pyranose rings is observed at $1,025 \mathrm{~cm}^{-1}$. The presence of ferrite nanoparticles can be confirmed by observing a peak at $587 \mathrm{~cm}^{-1}$ (Gang et al. 2010). Here, the peak corresponding to furosemide moieties is not observed due to the minimum quantity and the dominant FTIR peaks of starch. Figure $4 \mathrm{~b}$ represents the FTIR spectrum of $\mathrm{Fe}_{3} \mathrm{O}_{4}$-furosemide-starch prepared under alkaline condition. Here also one can see the peaks corresponding to the $-\mathrm{OH}, \mathrm{C}-\mathrm{H},-\mathrm{OH}$ bending, $\mathrm{C}-\mathrm{O}-\mathrm{C}$ and $\mathrm{M}-\mathrm{O}$ stretchings. The important peak noted here is the appearance of a new peak at $1,593 \mathrm{~cm}^{-1}$ corresponding to the $\mathrm{O}^{-} \mathrm{Na}^{+}$like ionic structure. It indicates that during the sodium hydroxide treatment all the $-\mathrm{OH}$ groups are converted into $\mathrm{O}^{-} \mathrm{Na}^{+}$like structure. Further, the added sodium hydroxide stabilized the crystal structure of furosemide-functionalized ferrite as a nucleating agent. Figure $4 \mathrm{c}$ shows the FTIR spectrum of $\mathrm{Fe}_{3} \mathrm{O}_{4}$-furosemide-starch prepared under neutral $\mathrm{pH}$. The present system also exhibits $-\mathrm{OH}, \mathrm{C}-\mathrm{H}, \mathrm{C}-\mathrm{O}-\mathrm{C}$ and metal oxide stretching. The $-\mathrm{OH}$ bending vibration can be seen at $1,641 \mathrm{~cm}^{-1}$. The $\mathrm{C}-\mathrm{H}$ bending vibration is observed as a broad peak.

\section{UV-visible spectroscopy}

The UV-visible spectrum explains the possible electron transition in the chemical structure. Figure $\mathrm{S} 1 \mathrm{a}$ is 

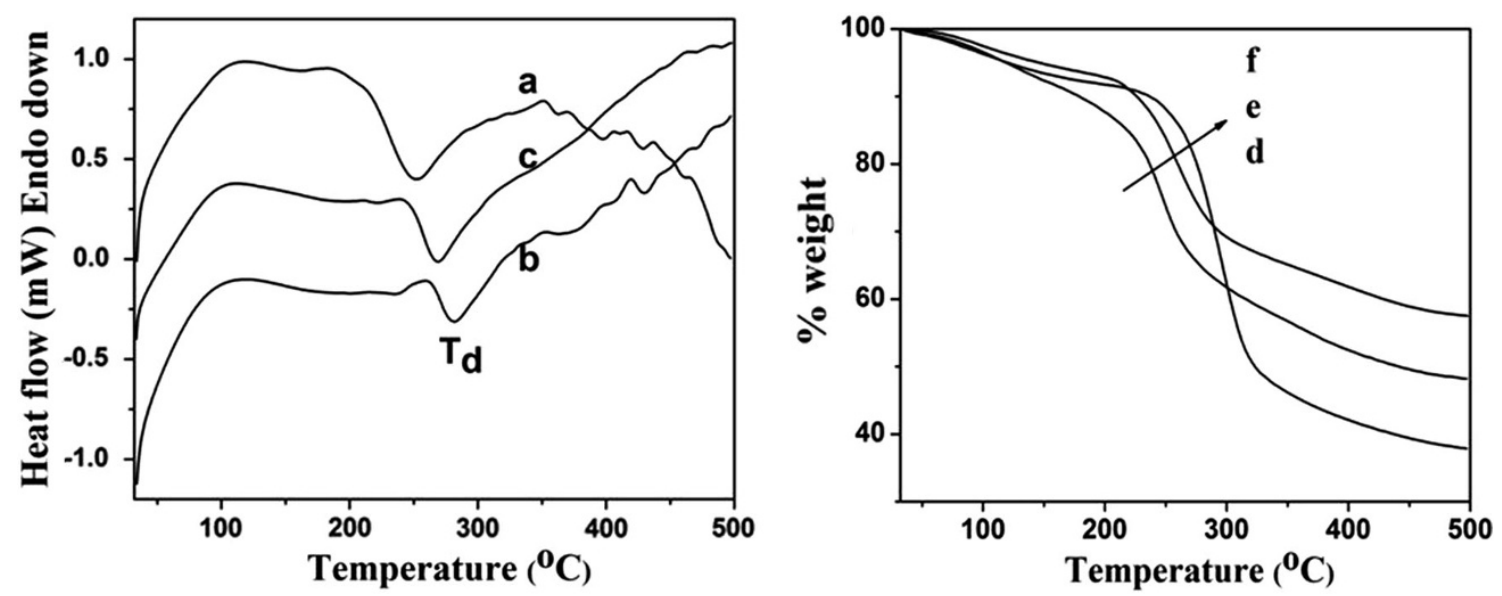

Fig. 5 DSC thermogram of ferrite-furosemide-starch synthesized under a acidic $\mathrm{pH}$, b alkaline $\mathrm{pH}$, $\mathbf{c}$ neutral $\mathrm{pH}$ and TGA of ferritefurosemide-starch synthesized under $\mathbf{d}$ acidic $\mathrm{pH}$, e alkaline $\mathrm{pH}, \mathbf{f}$ neutral $\mathrm{pH}$

responsible for the UV-visible spectrum of $\mathrm{Fe}_{3} \mathrm{O}_{4}-$ furosemide-starch prepared under acidic $\mathrm{pH}$. One broad hump at $277.8 \mathrm{~nm}$ is observed and corresponds to the $\mathrm{n} \rightarrow \pi$ transition of the hydroxyl group. $\mathrm{Fe}_{3} \mathrm{O}_{4}$-furosemide-starch prepared under alkaline $\mathrm{pH}$ (Fig. S1b) exhibits two peaks. The first peak around $280 \mathrm{~nm}$ is corresponding to the $\mathrm{n} \rightarrow \pi^{*}$ transition. The second small hump around $365 \mathrm{~nm}$ describes the presence of ferrite (Ahmad et al. 2009). The UV-visible spectrum of $\mathrm{Fe}_{3} \mathrm{O}_{4}$-furosemide-starch prepared under neutral $\mathrm{pH}$ (Fig.S1c). Peaks corresponding to Fig.S1a are also observed here. On thorough analysis, the UV-visible results indicated that $\mathrm{Fe}_{3} \mathrm{O}_{4}$ prepared under acidic $\mathrm{pH}$ simply degrade the ferrite structure. Hence, a peak corresponding to ferrite is absent in the spectrum.

\section{DSC study}

The DSC thermogram of $\mathrm{Fe}_{3} \mathrm{O}_{4}$-furosemide-starch prepared under three different $\mathrm{pHs}$ is shown in Fig. 5ac. Starch treated under acidic $\mathrm{pH}$ exhibited the degradation temperature at $252{ }^{\circ} \mathrm{C}$. Starch treated under alkaline $\mathrm{pH}$ shows the degradation temperature at $281.2{ }^{\circ} \mathrm{C}$. The starch treated under neutral $\mathrm{pH}$ exhibited the same at $268.3^{\circ} \mathrm{C}$. On close comparison, starch treated at all pHs does not show the melting temperature. Above all, the starch treated under alkaline $\mathrm{pH}$ exhibited the highest degradation temperature due to the formation of ionic structure of starch; i.e., the formation of $\mathrm{O}^{-} \mathrm{Na}^{+}$like ionic structure. Liu et al. (2009) studied the DSC of gelatinized starch. The $T_{\mathrm{g}}$ of starch was varied with the moisture content of the starch sample. In the present investigation, the $T_{\mathrm{g}}$ did not clearly appear due to the presence of chemical interaction between the starch and the hydrophilic furosemide-functionalized ferrite.

\section{TGA profile}

The thermal stability of starch treated at three different $\mathrm{pHs}$ in the presence of furosemide-functionalized ferrite is given in Fig. 5d-f. Figure 5d enumerates the TGA thermogram of starch treated under acidic $\mathrm{pH}$. The thermogram exhibits a three-step degradation process. The first minor weight loss below $100{ }^{\circ} \mathrm{C}$ is associated with the removal of physisorbed water molecules. The second major weight loss up to $200{ }^{\circ} \mathrm{C}$ corresponds to the removal of chemisorbed water molecules. The third major weight loss around $270{ }^{\circ} \mathrm{C}$ is due to the breaking of intramolecular ether linkage, and the molecular weight of starch was suddenly decreased. After the degradation, it shows $38.5 \%$ weight residue remains around $500{ }^{\circ} \mathrm{C}$. Piyada et al. (2013) reported about the depolymerization of starch around 250-300 ${ }^{\circ} \mathrm{C}$ and led to the decrease in molecular weight of starch. Our results are merged with their reports. Figure $5 \mathrm{e}$ is corresponding to the degradation of starch treated in the presence of furosemide-functionalized ferrite under alkaline and neutral pHs, respectively. Here also one can observe a three-step degradation process with the percentage weight residue of 48.9 and $58.5 \%$ around $500{ }^{\circ} \mathrm{C}$, respectively (Fig. 5e, f). In overall comparison, the starch treated under acidic $\mathrm{pH}$ exhibited the lowest percentage weight residue, whereas the starch treated under neutral $\mathrm{pH}$ shows the highest percentage weight residue. Under acidic $\mathrm{pH}$, the structure of ferrite was degraded and as a result exhibited the remaining lowest weight residue.

\section{SEM history}

The surface morphology of starch treated under acidic $\mathrm{pH}$ is shown in Fig. 6a. The morphology exhibited a broken stone-like surface due to the dispersion of nanoferrite. The diameter of the starch was determined as $9 \times 10^{-6} \mathrm{~m}$. 

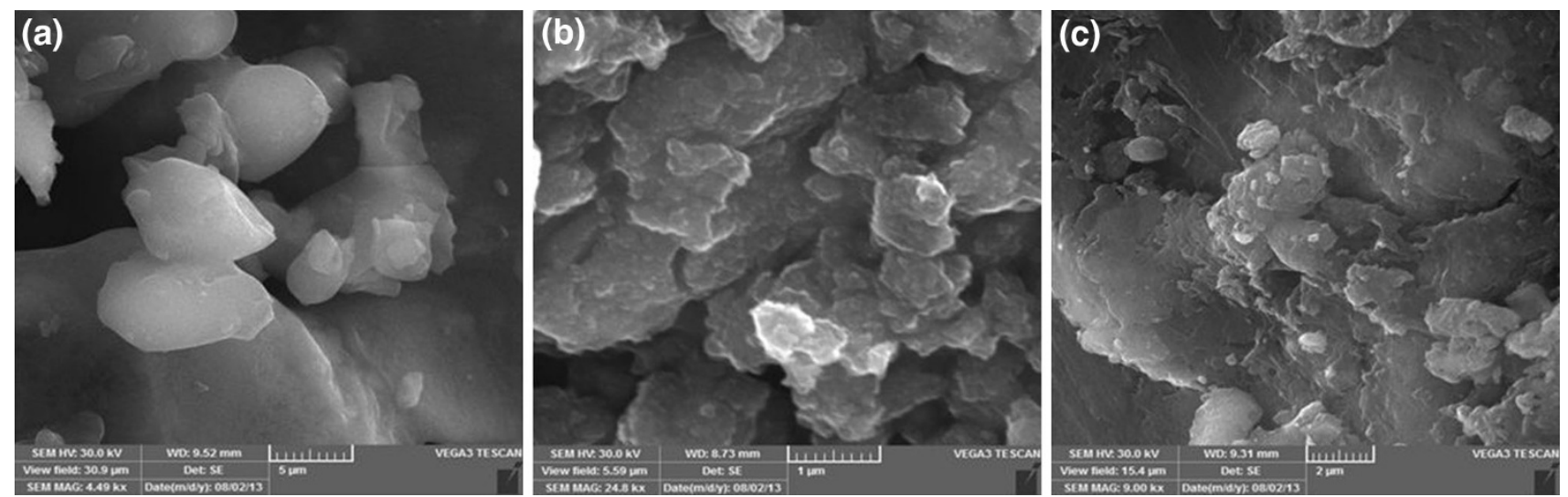

Fig. 6 SEM image of ferrite-furosemide-starch prepared under a acidic $\mathrm{pH}, \mathbf{b}$ alkaline $\mathrm{pH}$, $\mathbf{c}$ neutral $\mathrm{pH}$

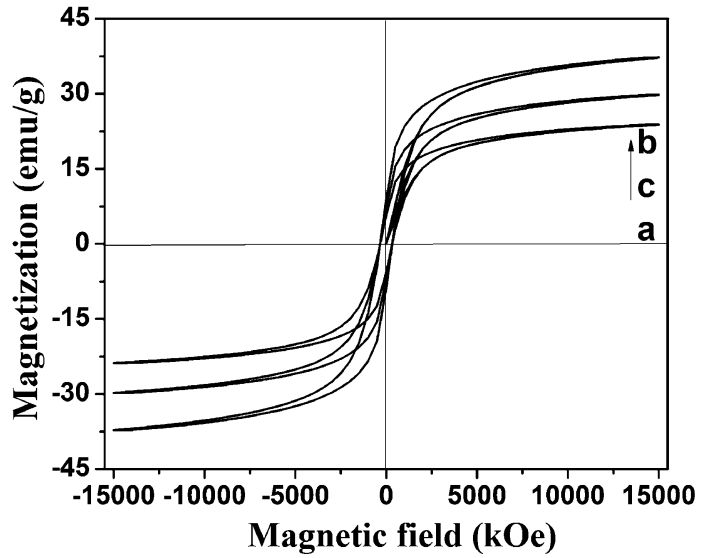

Fig. 7 VSM loops of ferrite-furosemide-starch prepared under a acidic $\mathrm{pH}, \mathbf{b}$ alkaline $\mathrm{pH}$, c neutral $\mathrm{pH}$

Figure $6 \mathrm{~b}$ defines the surface morphology of nanoferrite with broken stone-like morphology. The surface morphology of enzymatic hydrolyzed starch was found to be a broken stone-like surface morphology with microporous structure (Le Corre et al. 2012). Here, the size was determined as $1.5 \times 10^{-6} \mathrm{~m}$. This is due to the additional nucleation effect of $\mathrm{NaOH}$. The surface morphology of starch treated under neutral medium in the presence of furosemide-functionalized ferrite is shown in Fig. 6c. Here also one can observe a broken stone-like morphology with the distribution of furosemide-functionalized ferrite. Under neutral medium, the size of ferrite was determined as $24 \times 10^{-6} \mathrm{~m}$. On comparison, the starch treated under $\mathrm{NaOH}$ medium exhibited the lowest size due to the nucleation and compact close-packing effects on starch induced by the added $\mathrm{NaOH}$.

\section{VSM study}

The VSM value of starch/ $/ \mathrm{Fe}_{3} \mathrm{O}_{4}$-furosemide system under different $\mathrm{pH}$ is given in Fig. 7. Figure $7 \mathrm{a}$ indicates the
VSM loop of starch/ $\mathrm{Fe}_{3} \mathrm{O}_{4}$-furosemide system prepared under acidic condition, with the VSM value of $22.4 \mathrm{emu} / \mathrm{g}$. Figure $7 \mathrm{~b}$, c represents the VSM loops of starch/ $\mathrm{Fe}_{3} \mathrm{O}_{4}$ furosemide system prepared under alkaline and neutral $\mathrm{pH}$ with the magnetization values of 34.4 and $28.1 \mathrm{emu} / \mathrm{g}$, respectively. Under alkaline $\mathrm{pH}$, the ferrite gets nucleated and the size of ferrite gets reduced yielding a higher VSM value. In the case of acidic $\mathrm{pH}$, the crystal structure of ferrite was degraded and yielded a low VSM value. On critical comparison with the pristine Ferrite, the nanocomposite system gave a lower value. This is due to the thin layer-like coating of starch on the surface of Ferrite (Vinod et al. 2008; Aouak et al. 2013). The sedimentation velocity of starch/ $\mathrm{Fe}_{3} \mathrm{O}_{4}$-furosemide system under neutral $\mathrm{pH}$ exhibited the larger-size starch particles and settled down very fast with higher sedimentation velocity.

\section{Sedimentation study}

The sedimentation velocity of starch treated under three different $\mathrm{pHs}$ in the presence of furosemide-functionalized ferrite is described below. The sedimentation velocity of starch depends on the amount, charge, size and shape of the material. The furosemide-functionalized $\mathrm{F}_{3} \mathrm{O}_{4}$ concentration was varied between 0.5 and $1 \%$ weight and indicated by a, b, c, d, and e, respectively. In the present investigation, the starch treated under neutral medium exhibited the highest sedimentation velocity of $12.415 \times 10^{-6} \mathrm{~m} / \mathrm{s}$. This is due to the larger size of starch, and hence increases in gravitational force. Figure $8 \mathrm{a}$ indicates the effect of time on sedimentation height at five different concentrations. Figure $8 \mathrm{~b}$ represents the plot of time against sedimentation height for the $\mathrm{Fe}_{3} \mathrm{O}_{4}$-furosemide-starch system treated under alkaline $\mathrm{pH}$. The SEM analysis indicates that the size of starch was determined as $1.5 \times 10^{-6} \mathrm{~m}$, and hence the sedimentation velocity was found to be very low, i.e., $0.53 \times 10^{-6} \mathrm{~m} / \mathrm{s}$. Figure $8 \mathrm{c}$ confirms the sedimentation 
(a)

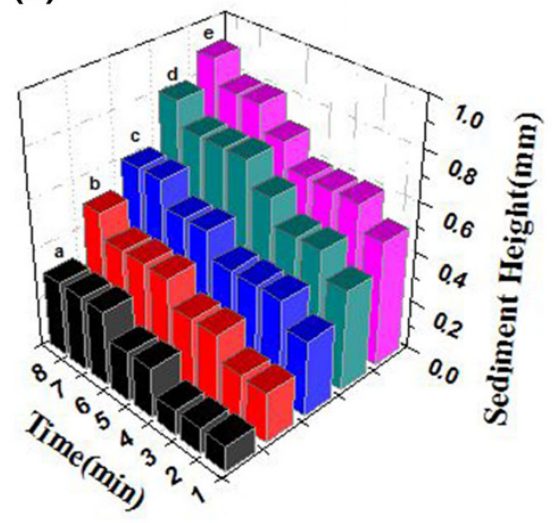

(b)

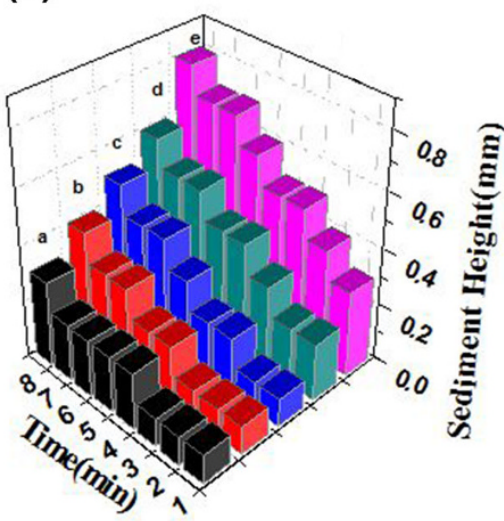

(c)

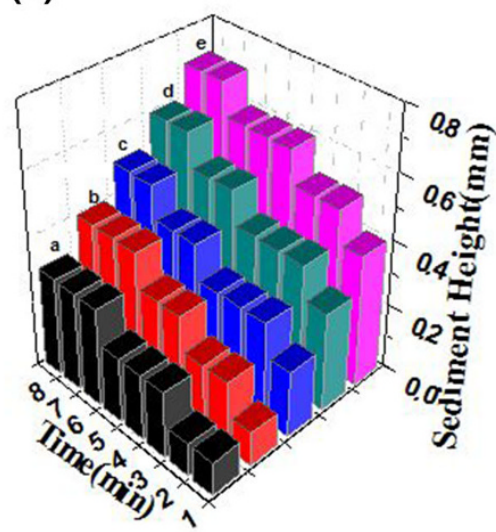

Fig. 8 Sedimentation height of ferrite-furosemide-starch system prepared under a acidic $\mathrm{pH}, \mathbf{b}$ alkaline $\mathrm{pH}$, $\mathbf{c}$ neutral $\mathrm{pH}$ at different concentrations

behavior of starch under neutral $\mathrm{pH}$ in the presence of furosemide-functionalized ferrite. Hence, the sedimentation velocity was calculated as $1.875 \times 10^{-6} \mathrm{~m} / \mathrm{s}$. On comparison, it is found that the sedimentation velocity of starch depends on the size of the starch and $\mathrm{pH}$ of the medium. In the presence of the alkaline medium, the system exhibited the lowest sedimentation velocity. This is due to the absence of both inter- and intramolecular hydrogen bonding. Under alkaline $\mathrm{pH}$, all the $\mathrm{OH}$ groups of starch were converted into $\mathrm{O}^{-} \mathrm{Na}^{+}$like structures. But in the case of neutral $\mathrm{pH}$, both inter- and intramolecular forces of attraction were not disturbed. Recently, Sajeev et al. (2002) studied the settling behavior of different starches under different experimental conditions. In the presence of surface-functionalized ferrite, the starch molecules settled very fast due to the combined effect of gravitational force, magnetic force and electrostatic interactions.

\section{Conclusions}

The niche points of the present investigation is summarized here as conclusion. The FTIR spectrum confirmed the surface-functionalized ferrite $\left(1,015 \mathrm{~cm}^{-1}\right)$ by furosemide. The appearance of various crystal planes such as $d_{311}, d_{400}$ and $d_{533}$ in the XRD declared the formation of ferrite. After the surface functionalization of ferrite with furosemide, the VSM value was decreased to $42.7 \mathrm{emu} / \mathrm{g}$. In the FTIR spectrum, a peak around $587 \mathrm{~cm}^{-1}$ confirmed the furosemide-functionalized ferrite nanoparticles in the $\operatorname{starch} / \mathrm{Fe}_{3} \mathrm{O}_{4}$ nanocomposite system. The starch/ $/ \mathrm{Fe}_{3} \mathrm{O}_{4}$ nanocomposite system under alkaline $\mathrm{pH}$ exhibited the highest thermal degradation temperature due to the formation of $\mathrm{O}^{-} \mathrm{Na}^{+}$like ionic structure. Starch treated under neutral $\mathrm{pH}$ in the presence of furosemide-functionalized ferrite exhibited the highest sedimentation velocity $\left(12.415 \times 10^{-6} \mathrm{~m} / \mathrm{s}\right)$ due to the bigger size of the starch particles.

Acknowledgments The authors sincerely acknowledge Mrs. G. Vijayalakshmi, Assistant Professor in English for her valuable help during this manuscript preparation work.

Open Access This article is distributed under the terms of the Creative Commons Attribution License which permits any use, distribution, and reproduction in any medium, provided the original author(s) and the source are credited.

\section{References}

Ahmad S, Riaz U, Kashik A, Alam J (2009) Soft template synthesis of super paramagnetic ferrite nano particles a novel technique. J Inorg Organomet Polym 19:355-360

Aouak T, Deraz NM, Alarifi AS (2013) Synthesis, non-isothermal crystallization and magnetic properties of cobalt zinc ferrite/ poly(ethylene-co-vinylalcohol) nano composite. Bull Mater Sci $36: 417-427$

Bin WF, Jie C, Cong HK, Qin LS (2009) Preparation and electrochemical performance of spherical $\mathrm{Fe}_{3} \mathrm{O}_{4}$ as an anode material for Li-ion batteries. Sci China Ser E: Tech Sci 52:3219-3223

Chen BA, Zai YY, Wang XM, Cha NN (2008) Synergistic effect of the combination of nanoparticles $\mathrm{Fe}_{3} \mathrm{O}_{4} \mathrm{Au}$ with daunomycin on K562/AO2 cells. Int J Nanomater 3(3):343-350

Closs CB, Petit BC, Roberts ID, Esher ID (1999) Phase separation and rheologies of aqueous starch/gallactomannan systems. Carbohydr Polym 39:67-77

Da G, Ferret F, Marechal PA, Thanch MC, Marouze ML, Dutour D (2010) Modeling small scale cassava starch extraction. Simulation of reduction of water consumption through a recycling process. Prog Biochem 45:1837-1842

Gang ZY, Yu SH, Dong PS, Qin HM (2010) Synthesis, characterization and preparation of ethylenediamine functionalized $\mathrm{Fe}_{3} \mathrm{O}_{4}$ magnetic polymers for the removal of $\mathrm{Cr}(\mathrm{iv})$ in wastewater. J Hazard Mater 182:295-302

He YP, Wang SQ, Li CR, Miao YM, Wu ZY, Zou BS (2005) Synthesis and characterization of functionalized silica coated 
$\mathrm{Fe}_{3} \mathrm{O}_{4}$ superparamagnetic nanocrystals for biological applications. J Phys D: Appl Phys 38:1342-1350

Huang SH, Juang RS (2011) Biochemical and biomedical applications of multifunctionalized magnetite nanoparticles: a review. J Nanopart Res 13:4411-4430

Jiang L, Sun W, Kim J (2007) Preparation and characterization of $\mathrm{Fe}_{3} \mathrm{O}_{4}$ functionalized polystyrene magnetite nano composite. Mater Chem Phys 101:291-296

Kim MJ, Jang DH, Choa YH (2010) Preparation and characterization of carboxyl functionalisation of magnetic nanoparticles for oligo nucleotide immobilization. Phy Scr T139:1-4

Klokkenburg M, Hilhorst J, Erne BH (2007) Surface analysis of magnetite nanoparticles in cyclohexane solutions of oleic acid and oleylamine. Vib Spectrosc 43:243-248

Koussi GK, Wang P, Sreevatan S, Irudhayaraj J (2007) Aptamer mediated magnetite and gold coated magnetite nanoparticles as detection assay for prion protein assessment. Biotechnol Prog 23(1239): 1244

Le Corre D, Vahanian E, Dufresne A, Bras J (2012) Enzymatic pretreatment for preparing starch nano crystals. Biomacromolecules 13:132-137

Li Z, Sun Q, Gao M (2005) Preparation of water soluble magnetic nanocrystals from hydrated ferrite salts in 2-pyrrolidine: meal leading to $\mathrm{Fe}_{3} \mathrm{O}_{4}$. Angew Chem 44:123-126

Liu P, Yu L, Liu H, Li L (2009) Glass transition temperature of starch studied a high speed DSC. Carbohydr Polym 77:250-253

Madariaga BC, Aquirre JA (2011) Combination treatment of corn starch waste water by sedimentation, microfiltration and reverse osmosis. Desalination 279:285-290

Mos SH, Shri S, Antwerp MV, Cao Z, Baker JR (2007) Dendrimer functionalized ironoxide nanoparticles for specific targeting and imaging of cancer cells. Adv Funct Mater 17:3043-3050
Piyada K, Waranyou S, Thawien W (2013) Mechanical, thermal and structural properties of rice starch reinforced with rice starch nano crystals. Int Food Res J 20:439-449

Prakash A, McCormick AV, Zachariah MR (2004) Aero-sol-gel synthesis of nanoporous iron oxide particles: a potential oxidizer for nano energetic materials. Chem Mater 16:1466-1471

Sajeev, Kaliappan R, NarayananVVS, Thangavel K (2002) Kinetics of gravity settling of cassava starch in aqueous suspension. Biosyst Eng 83(3):327-337

Sun J, Zhou S, Hou P, Yang Y, Li X, Li M (2007) Synthesis and characterization of bio-compatible $\mathrm{Fe}_{3} \mathrm{O}_{4}$ nanoparticle. J Biomed Mater Res A 80:333-341

Tian XZ, Wang JF, Qian SW, Wu WJ, Gang X (2010) Preparation and properties of $\mathrm{F}_{3} \mathrm{O}_{4}$ biomimetic micro-nano structure coatings. Adv Nat Sci 3(2):299-305

Vinod TP, Chang JH, Kim JW, Ree SW (2008) Self assembly and photopolymerization of diacetylene molecules on surface of magnetic nano particles. Bull Korean Chem Soc 29:799-804

Wei Y, Cheng S, Zheng Y (2008) Synthesis and floculating properties of cationic starch derivatives. Carbohydr Polym 74:673-679

Xiao ZP, Yang KM, Liang H, Lu J (2010) Synthesis of magnetic, reactive and thermo responsive $\mathrm{F}_{3} \mathrm{O}_{4}$ nanoparticle via surface initiated RAFT copolymerization of $\mathrm{N}$-isopropyl-acrylamide and acrolein. J Polym Sci Part A: Polym Chem 48:542-550

Zhou Y, Wang S, Xie Y, Guang W, Dirz B, Yang Z, Jiang X (2008) 1, 3-dipolar cycloaddition as a general route for functionalization of $\mathrm{F}_{3} \mathrm{O}_{4}$ nanoparticle. Nanotechnology 19:1-5 